\title{
JUTZPA, UN ACERCAMIENTO PRELIMINAR AL PENSAMIENTO DE EMMANUEL LEVINAS
}

\author{
Ana Maria Tapia Adler \\ Facultad de Filosofia y Humanidades \\ Directora del Centro de Estudios Judaicos \\ Universidad de Chile \\ amta@uchile.cl
}

\begin{abstract}
RESUMEN
El presente articulo parte de la base de la lectura de algunos artículos de Emmanuel Levinas, principalmente los que han sido rcunidos en su libro Dificil Libertad, a través de los cuales quien escribe realiza una aproximación personal al pensamiento de este autor, desde una perspectiva judaica.
\end{abstract}

Palabras Clave: Levinas, judaísmo, otredad, alteridad, pensamiento judio, pensadores judios.

\section{ABSTRACT}

After reading some articles of Emmanuel Levinas, mainly those assembled in the book $\mathrm{Di}$ ficil Libertad, the author of this article wrote a personal approach to the thinking of Levinas, and she did it from a Jewish perspective.

KEY WoRDS: Levinas, Judaism, otherness, the other, Jewish thought, Jewish philosophers.

\section{A MODO DE INTRODUCCIÓN}

Lo primero que debo especificar es la singularidad del título de un escrito que no pretende ser un estudio filosófico,-porque no es mi campo-, sino una lectura desde la periferia, de alguien que se acerca tímida y respetuosamente a uno de los pensadores más importantes del siglo XX. De alli el término jutzpá, proveniente del hebreo y que me atreveria a traducir como "atrevimiento, osadía, audacia".

La personal aproximación a Levinas es producto de la curiosidad que despertó en mí el gran revuelo producido por las continuas consultas y peticiones de sus libros en nuestro Centro de Estudios Judaicos y el que se trate de un pensador judío, practicante y perteneciente a la vertiente conocida como "ortodoxa" u observante. 
La dificultad en la lectura de algunos de sus artículos fue evidente. Para una buena comprensión se hace necesario entender los supuestos que subyacen en ellos y un conocimiento más profundo de distintos pensadores que han marcado la disciplina filosófica. En definitiva, pareciera ser que alguien ajeno al campo de la filosofia, $o$ al menos no poseedor de una sólida formación en ella, no lograria entender sus escritos.

Después de haber leído algunos de sus textos en los que hace mención directamente al judaísmo concluyo, por propia experiencia, que Levinas no es de lectura fácil. Lo que ha corroborado el Prof. Shalom Rosenberg cada vez que se ha referido a la obra de este pensador.

Sin embargo, ha sido un grato descubrimiento el reencontrarme con aspectos importantes del "ser judío en el mundo" y de la misión de "letaken 'olam" (reparar el mundo) que debe cumplir todo judío en su rol de socio de Dios en el milagro de la creación, actitud que empieza, en definitiva, con un adecuado acercamiento hacia "el otro".

Estas líneas son, pues, una suma de pensamientos y reflexiones surgidas de la lectura de los artículos publicados en su obra Dificil Libertad, y que no necesariamente siguen el orden de los mismos.

En el artículo denominado "Judaísmo"' Levinas señala que "la palabra 'judaismo' se refiere, en nuestra época, a conceptos muy diversos". El judaismo es complejo. No puede ser entendido en un sentido meramente religioso, porque el judaísmo no es una religión. $\mathrm{O}$, dicho de otro modo, el judaísmo es más que religión, es una forma de vida, una forma de sentir, de pararse y actuar en el mundo tratando de que cada acción humana se transforme en un medio de comunicación con Dios. Esta forma de vida se encuentra normada por una serie de conductas que se relacionan con todos y cada uno de los aspectos de la vida del judío, basada en el código de conducta que fue revelada por Dios, en el Monte Sinaí, a través de Moisés².

La aceptación de la Revelación (Torá) constituye el pacto entre Dios e lsrael y es, en sí, el fundamento del monoteísmo ético, la creación más original del judaísmo, que se encuentra ligado indisolublemente a la existencia del pueblo judio y su historia y a través del cual lsrael debe conformar una nación santa que viva de acuerdo con la voluntad de Dios expresada en la Torá y explicitada en el Talmud.

Cfr. Dificil Libertad, Fundación David Calles, Bs. Aires, Argentina, 2005, pp. $115-118$.

El culto incluye ritos y prácticas en las que, además de las tres oraciones diarias, está la declaración de la unicidad de Dios al levantarse y al acostarse y las oraciones de gracias al despertar. El ciclo de vida, con ritos de pasajes que van marcando cada una de las etapas de un ser humano, la kashnut, palabra que deriva de kasher, que significa "apto", tanto en lo relacionado con las actitudes como con los alimentos, lo que es apto para hacer y lo que es apto o está permitido comer; en este rubro no solo es importante to que se come sino también cómo se preparan los alimentos y cómo se comen (brajot). El ciclo del año judio, que incluye la celebración de fiestas y el cumplimiento de ayunos, todos ellos relacionados con la historia del pueblo judío. La relación con nuestro prójimo, etc. (Tapia 1998). 
Tanto en la Torá como en el Talmud, encontramos leyes y mandatos que, en su conjunto, formaron la "legislación" judaica conocida con el término de Halajá y que representa el sistema legal del judaísmo.

Los conceptos antes mencionados, Torá, Talmud y Halajá, ameritan una suerte de explicación. Los dos primeros encierran el concepto de "enseñanza, instrucción", el tercero deriva de la raiz "holej", que significa "andar, caminar" por el sendero que traza la "enseñanza". Porque como muy bien escribe Levinas "La Biblia no apunta al verdadero conocimiento de Dios, sino tan solo a la enseñanza de una regla práctica de vida, inspirada por el amor desinteresado de Dios"

Un midrash, relato tradicional resumido por Levinas ${ }^{4}$, ilustra dos posiciones judaicas diferentes ante un mismo hecho:

"Cierta vez se acercó un pagano hasta rabi Shammai, uno de los grandes sabios de la época del Talmud y le dijo: "Estoy dispuesto a convertirme al judaismo si tú eres capaz de enseñarme la esencia de la Torá en el lapso de tiempo en que puedo estar parado en un pie". El rabino se enojó y le dijo que no era posible hacerlo. Entonces, este hombre acudió a Rabí Hillel y le hizo el mismo desafio. El sabio lo miró y le dijo: no le hagas a otro lo que no quisieres que te hicieren a ti, el resto es comentario. Ve y estudia.

"Ve y estudia". El estudio es un elemento de vital importancia para los judios. Por supuesto que al hablar de estudio lo hace en el sentido en que lo señalaba el sabio Hillel, esto es, entender que el "estudio por el estudio" no posee mérito alguno si no va acompañado de la praxis, porque el judaísmo es acción. Presupongo que es por esta razón y por el temor que se siente ante el fenómeno de la asimilación, que Levinas reflexiona sobre estos temas en su obra Dificil Libertad ${ }^{5}$.

La Torá está llena de ejemplos a través de los cuales se va indicando al hombre modos de comportamiento y enseñándole cómo "ser y estar" en el mundo: Veamos tres ejemplos:

Ejemplo 1: Génesis cap. 1, Relato de la Creación.

"Y dijo Dios ¡hagamos al hombre!!...[y el texto dice] "y creó Dios al hombre, varón y hembra los creó".

El texto indica que todos descendemos de la misma pareja humana y, por lo tanto, todos los hombres somos iguales y tenemos los mismos derechos, sin distinción de raza, color, religión o cultura. Nadie puede decirse superior a otro. Todos los hombres somos iguales, pero cada uno

Cfr. "¿Has releído a Baruch?", op. cit., 143.

Cfr. “¿Cómo es posible el judaismo?”, op. cit,, 247.

Cfr. "Reflexiones acerca de la educación judia" y "La asimilación hoy", op. cit., 257 y ss. 251 y ss,, respectivamente. 
conforma un mundo. Luego, percibimos como normal la existencia de igualdad dentro de la diversidad, dentro de la pluralidad. Todos, a la vez, tenemos la posibilidad de ser salvos aun cuando no cumplamos con igual corpus de preceptos. De hecho, Levinas en "Israel yel universalismo"6 hace mención a que un hombre no perteneciente a ninguna de las religiones monoteístas le basta con solo cumplir las leyes noajidas.

Las leyes noájidas que fueron entregadas a las naciones son siete:

1) La primera dice relación con la prohibición de adorar ídolos

2) La segunda señala que no debe maldecirse al Eterno

3) La tercera condena el asesinato

4) El cuarto mandato prohíbe el incesto y el adulterio

5) El quinto se refiere a no hurtar

6) El sexto precepto, que pudiera parecer extraño a nuestros ojos, señala que no debe comerse came trozada de un animal vivo

7) El séptimo y último de los preceptos ordena establecer cortes de justicia

Ejemplo 2: Éxodo 20 y Deuteronomio.5:

Alli aparecen los Aseret Dibrot (10 Mandamientos). Estos preceptos están divididos en dos tipos, los primeros referidos a la relación entre Dios y el hombre, y los restantes ló están en relación del hombre y su prójimo.

A continuación, los preceptos entre el hombre y Dios, en las dos versiones aparecidas en la Torá.

$6 \quad$ Op. cit., 199. 


\begin{tabular}{|c|c|c|}
\hline & ÉXODO 20 & DEUTERONOMIO 5 \\
\hline 1 & $\begin{array}{l}\text { Yo soy Jehová tu Dios, que te saqué de la } \\
\text { tierra de Egipto, de casa de servidumbre } \\
\text { (V2) No tendrás dioses ajenos delante de } \\
\text { mi. (V3) }\end{array}$ & $\begin{array}{l}\text { Soy Jehová tu Dios, que te saqué de tierra } \\
\text { de Egipto, de casa de servidumbre. (V6) } \\
\text { No tendrás dioses ajenos delante de mí. } \\
\text { (V7) }\end{array}$ \\
\hline 2 & $\begin{array}{l}\text { No te harás imagen, ni ninguna semejanza } \\
\text { de lo que esté arriba en el cielo, ni abajo } \\
\text { en la tierra, ni en las aguas debajo de la } \\
\text { tierra. (V4) No te inclinarás a ellas, ni las } \\
\text { honrarás; porque yo soy Jehová tu Dios, } \\
\text { fuerte, celoso, que visito la maldad de los } \\
\text { padres sobre los hijos hasta la tercera y cu- } \\
\text { arta generación de los que me aborrecen, } \\
\text { (V5) y hago misericordia a millares, a los } \\
\text { que me aman y guardan mis mandamien- } \\
\text { tos. (V6) }\end{array}$ & $\begin{array}{l}\text { No harás para ti escultura, ni imagen } \\
\text { alguna de cosa que está arriba en los cielos, } \\
\text { ni abajo en la tierra, ni en las aguas debajo } \\
\text { de la tierra. (V8) No te inclinarás a ellas } \\
\text { ni las servirás; porque yo soy Jehová tu } \\
\text { Dios, fuerte, celoso, que visito la maldad } \\
\text { de los padres sobre los hijos hasta la } \\
\text { tercera y cuarta generación de los que me } \\
\text { aborrecen, (V9) y que hago misericordia a } \\
\text { millares, a los que me aman y guardan mis } \\
\text { mandamientos. (V10) }\end{array}$ \\
\hline 3 & $\begin{array}{l}\text { No tomarás el nombre de Jehová tu Dios } \\
\text { en vano; porque no dará por inocente } \\
\text { Jehová al que tomare su nombre en vano. } \\
\text { (V7) }\end{array}$ & $\begin{array}{l}\text { No tomarás el nombre de Jehová tu Dios } \\
\text { en vano; porque Jehová no dará por } \\
\text { inocente al que tome su nombre en vano. } \\
\text { (V11 }\end{array}$ \\
\hline 4 & $\begin{array}{l}\text { Acuérdate del día de reposo para santifi- } \\
\text { carlo. (V8) } \\
\text { Seis días trabajarás, y harás toda tu obra; } \\
\text { (V9) mas el séptimo día es reposo para } \\
\text { Jehová tu Dios; no hagas en él obra alguna, } \\
\text { tú, ni tu hijo, ni tu hija, ni tu siervo, ni tu } \\
\text { criada, ni tu bestia, ni tu extranjero que } \\
\text { está dentro de tus puertas. (V10) } \\
\text { Porque en seis días hizo Jehová los cielos } \\
\text { y la tierra, el mar, y todas las cosas que en } \\
\text { ellos hay, y reposó en el séptimo dia; por } \\
\text { tanto, Jehová bendijo el día de reposo y lo } \\
\text { santificó. (V11) }\end{array}$ & $\begin{array}{l}\text { Guardarás el dia de reposo para santificar- } \\
\text { lo, como Jehová tu Dios te ha mandado. } \\
\text { (V12) } \\
\text { Seis dias trabajarás, y harás toda tu obra; } \\
\text { (V13) mas el séptimo dia es reposo a } \\
\text { Jehová tu Dios; ninguna obra harás tú, ni } \\
\text { tu hijo, ni tu hija, ni tu siervo, ni tu sierva, } \\
\text { ni tu buey, ni tu asno, ni ningún animal } \\
\text { tuyo, ni el extranjero que está dentro de } \\
\text { tus puertas, para que descanse tu siervo y } \\
\text { tu sierva como tú. (V14) Acuérdate que } \\
\text { fuiste siervo en tierra de Egipto, y que } \\
\text { Jehová tu Dios te sacó de allá con mano } \\
\text { fuerte y brazo extendido; por lo cual } \\
\text { Jehová tu Dios te ha mandado que guardes } \\
\text { el día de reposo. (V15) }\end{array}$ \\
\hline
\end{tabular}


Los restantes, entre el hombre y su prójimo son:

\begin{tabular}{|c|c|c|}
\hline 5 & $\begin{array}{l}\text { Honra a tu padre y a tu madre, para que } \\
\text { tus dias se alarguen en la tierra que Jehová } \\
\text { tu Dios te da. (V12) }\end{array}$ & $\begin{array}{l}\text { Honra a tu padre y a tu madre como } \\
\text { Jehová tu Dios te ha mandado, para } \\
\text { que sean prolongados tus días, y para } \\
\text { que te vaya bien sobre la tierra que } \\
\text { Jehová tu Dios te da. (V16) }\end{array}$ \\
\hline 6 & No matarás. (13) & No matarás. (V17) \\
\hline 7 & No cometerás adulterio. (V14) & No cometerás adulterio. (V18) \\
\hline 8 & No hurtarás. (V15) & No hurtarás. (V19) \\
\hline 9 & $\begin{array}{l}\text { No hablarás contra tu prójimo falso } \\
\text { testimonio. (V16) }\end{array}$ & $\begin{array}{l}\text { No dirás falso testimonio contra tu } \\
\text { prójimo. (V20) }\end{array}$ \\
\hline 10 & $\begin{array}{l}\text { No codiciarás la casa de tu prójimo, no } \\
\text { codiciarás la mujer de tu prójimo, ni su } \\
\text { siervo, ni su criada, ni su buey, ni su asno, } \\
\text { ni cosa alguna de tu prójimo. (V17) }\end{array}$ & $\begin{array}{l}\text { No codiciarás la mujer de tu prójimo, } \\
\text { ni desearás la casa de tu prójimo, ni } \\
\text { su tierra, ni su siervo, ni su sierva, ni } \\
\text { su buey, ni su asno, ni cosa alguna de } \\
\text { tu prójimo. (V21) }\end{array}$ \\
\hline
\end{tabular}

Los preceptos entregados son válidos para todos. Observamos, entonces, que en el todos está la novedad revolucionaria. Asi, en relación al Shabbat señala Barylko: "Todos, sin excepción, un dia a la semana, debemos hacer un alto en la actividad usual y aprender a vivir de otra manera y aprender a vivir de otra manera es santificar"?.

Los mandamientos son normas destinadas a regular el comportamiento del individuo en sociedad, en comunidad y también en la globalidad.

En el Tanaj (AT) se aprecia la presencia activa de Dios que se manifiesta en la historia, orientándola en el sentido del establecimiento de la justicia y el derecho. Es "un Dios que toma partido por el pobre y que lo libera de la esclavitud y de la opresión ${ }^{8}$. El prójimo no es tan solo el judio, ya que en los textos aparece la presencia del forastero, que junto con la viuda y el huérfano constituyen una trilogia clásica".

Si bien es cierto que en la Biblia no encontramos un código organizado de derechos humanos no lo es menos que en ella hay diseminadas en los distintos libros que componen el Tanaj (AT) todo tipo de leyes en las que se reflejan los derechos inherentes a todo ser humano solo por el hecho de serlo y se recuerda la experiencia judía de haber sido forastero y esclavo en tierra extraña, razón por la cual el pueblo de Israel debe actuar en consecuencia.

7 Barylko, J, La Creación.

s Cf. M. H. Ellis, Apuntes para una teologia judia de la liberación, en: "Pasos" 1986, 15-22. 
Ejemplo 3: Otras citas bíblicas:

"Se te ha dicho, Oh hombre, lo que es bueno, lo que Dios reclama de ti: tan solo practicar la equidad, amar la piedad y andar humildemente con tu Dios" (Miqueas 6:8).

"No maltratarás al forastero ni lo oprimirás" (Ex 22:20).

"No maldecirás a un mudo, ni pondrás tropiezo ante un ciego" (Lv 19:14).

"Ama a tu prójimo como a ti mismo" ( $\mathrm{Lv}$ 19:18).

"Al forastero que reside junto a vosotros le mirareis como a uno de vuestro pueblo y le amarás como a ti mismo, pues forasteros fuisteis vosotros en la tierra de Egipto. Yo soy el señor vuestro Dios" (Lv 19:34).

$\mathrm{Y}$, por último,

"Nunca faltarán pobres en este pais, por esto te doy Yo este mandamiento: debes abrir tu mano a tu hermano, a aquel de los tuyos que es indigente y pobre en tu tierra (Dt. 15:11).

Quiero llamar la atención sobre la forma de redacción, hacia la vigencia del texto: Dice, "nunca faltarán pobres en este país". ¿Cuál país? El tuyo, donde vives y desarrollas tu vida. También este mandato es universal y está expresado, como muchos otros textos, en presente, estableciendo una relación tú/yo - aquilahora.

Los hombres debemos conversar en franco diálogo "tú y yo", conocernos, aprender a acercarnos "al otro" sin recelo, buscando un acercamiento a través del diálogo, aprendiendo que la acción auténtica es lo que vale, y lo que permite, como dice Levinas "devolverle al otro lo que se le debe, amarlo en la justicia, tal es la esencia de una verdadera acción"."

Dos afirmaciones importantes en su frase: amar en justicia y verdadera acción. Cada uno de los términos es de amplio espectro. Por justicia puede entenderse, entre otros términos, imparcialidad, equidad, igualdad, equilibrio; en otras palabras podríamos entender que amar en justicia puede o debería equivaler a medir al otro con la misma vara con que somos medidos. Sin hacer distinción de ninguna especie, aplicando los conceptos de No hagas a otro lo que no deseas que te hagan a ti, y Ama a tu prójimo como a ti mismo. Conceptos difíciles de implementar en un mundo como el nuestro, en que en el postmodernismo prima el individualismo y la necesidad de ver cumplidas las propias aspiraciones sin preocuparse por "el otro en su otredad".

La segunda afirmación, verdadera acción está referida a una acción positiva, efectiva, auténtica que implique compromiso con el otro que no siendo yo, es como yo. 
Aquí pueden entrar las religiones, considerados sistemas estructurados sobre la base del "deber ser" y que desde esa perspectiva marcan una forma de vida. El judaísmo, el cristianismo y el islam (orden de aparición en el tiempo) como religiones del Libro presentan a quienes creen en sus supuestos fundamentales un camino a seguir y normas que cumplir, $y$ en esas normas cumplen un rol esencial aquellas que regulan el modo de relacionarnos con el prójimo, entendiendo como tal a todo aquél que está a mi lado, a todo aquél que vislumbro en mi horizonte y con el que de un modo u otro me relaciono ahora que el mundo no es más que una gran aldea global.

Las enseñanzas, prácticas y normas contenidas en la Torá son aplicables a todos los hombres, aquí es donde reside la universalidad del judaísmo, idea fuerza en el pensamiento de Levinas.

Todo hace pensar que una verdadera acción implica que la enseñanza y el estudio se den en mayor profundidad y tener como meta una educación en valores que permita acercarnos a conversar, a conocernos, a aprender los unos de los otros, con respeto, buscando en primer lugar aquello que nos une.

Un estudio que siga la premisa del sabio Hillel a quien ya hemos citado anteriormente ${ }^{10}$. $Y$ respecto al estudio quisiera aun hacer mención a la opinión del filosofo japonés Kaibare Ekken en relación con el mismo tema y que nos permite señalar que el asunto del estudio es transversal a las diferentes culturas.

Escribió Kaibare Ekken: "Porque el fin del estudio no es solamente ampliar los conocimientos, sino formular el carácter. Su objeto es hacer de nosotros hombres cabales más que hombres doctos"'ll.

Asi pues, el estudio al que se refiere apunta a la "sabiduria". Según este mismo filósofo "la principal razón por la que las enseñanzas de los sabios no son más apreciadas por el pueblo reside en que los hombres doctos se esfuerzan en exhibir su saber en vez de esforzarse en vivir de acuerdo a las enseñanzas de los sabios".

Debemos diferenciar entre el docto, hombre erudito, culto e ilustrado que se precia de su conocimiento y el sabio, también enudito, pensador y estudioso, a quien no le interesa hacer alarde de su sabiduría, sino de hacer de ella una forma de vida que puedan emular los demás.

Pienso que Levinas nos insta a preguntarnos acerca del rol de nosotros, los hombres, como miembros que viven en socjedad, en esta, la actual o en la que existirá siglos más adelante, la famosa aldea global de la que tanto se habla, en la que todos estaremos conectados con todos y quizás más solos que nunca, porque el diálogo se hará a través de una fría pantalla en donde veremos imágenes que no representan la verdadera identidad e imagen de las personas, sino las que 
ellas se han creado, ex profeso, para darse a conocer al resto del mundo que pulula entre chats, cyber cafés, blogs, facebooks y Messenger, imágenes que no siempre se condicen con la realidad de lo que somos sino que muestra lo que aspiramos a ser con la finalidad de ser aceptados.

Levinas no piensa en ese tipo de sociedad; él señala una ruta sin dobleces, y nos insta a trabajar en el prototipo de hombre al que debemos aspirar, y al que es nuestra obligación ayudar a formar a través de una educación en valores: ese modelo apunta necesariamente hacia el ideal del "sabio" no del docto. Al de un hombre liberado de pre-juicios, que hable en lenguaje simple para evitar la in-comprensión, la in-comunicación, y que como una forma de promover el diálogo, sepa escuchar y compartir con "el otro", no competir.

La generalidad de lo que vemos nos hace pensar que el hombre, esa criatura creada a imagen y semejanza de Dios, ha perdido su humanidad, el individualismo aflora y el "Yo y mis necesidades" se transforma en la medida de todas las cosas, olvidando al prójimo. Olvidamos que los derechos van de la mano con los deberes y no queremos reconocer que el ejercer el libre albedrío conlleva "hacerse responsable" de nuestros actos.

En el judaísmo, el hombre pertenece al reino animal, terrenal, y dentro de ese reino y de ese mundo ha de realizar su esencia. Sin embargo, como ha sido hecho a imagen y semejanza de Dios, le fue entregado como misión conquistar y dominar, este mundo. Conquistarlo no en el sentido de despojar, robar, capturar asaltar u oprimir, y, dominarlo en el sentido de servirlo, respetarlo, hacerse responsable por él.

Responsabilidad implica compromiso, obligación, cumplimiento de su cometido, solidaridad. Cada día pareciera ser más difícil cumplir este cometido. Nos preguntamos: $¿ Q u e ́$ estamos haciendo? ¿Es este el mundo en el queremos vivir? Un mundo en el que a decir de Levinas "para las multitudes [...] la lectura del diario matutino se ha convertido en la plegaria de la mañana"? 12

En el texto bíblico se nos enseña que el hombre, a diferencia de los animales, no solo vive su vida sino que la piensa, es capaz de preguntar y preguntarse acerca de su puesto en el mundo, de la misión que le compete, de la relación que debe establecer entre él y su medio, entre él y su prójimo, entre él y su Creador.

El profeta Isaías habla de un tiempo en el que "el lobo yacerá con el cordero". En una sinagoga de Santiago, a la entrada, estaba escrito "Mi casa es casa de oración para todos los pueblos"13. En las afueras del edificio de la Naciones Unidas se lee el versículo "No alzará espada nación contra nación ni se ejercitarán más para la guerra".

13 Nos referimos a la antigua Sinagoga Sefaradi Maguen David, ubicada en la calle Santa Isabel 80. 
Nos compete a nosotros, los hombres de buena voluntad de todas las naciones, credos o colores, trabajar para que eso acontezca y la única forma de hacerlo es reconociéndose en el otro y reanudando el diálogo con Dios...

El judaísmo, con su mensaje del monoteísmo ético y la universalidad de un Dios creador, es señal plantada para las naciones. Estos aspectos no dogmáticos son esenciales para un diálogo interconfesional e intercultural, que propenda al conocimiento y al acercamiento al "otro".

Esta actítud decidida es la que reafirma la característica pluralista y respetuosa del júdaísmo que acepta la unidad del ser humano en tanto identidad universal común, le permite dialogar con todos, reconoce el derecho de cada individuo a ser diferente y lo respeta en su "otredad" e identidad individual. Y lo hace en tanto poseedor de una identidad cultural definida, también "otra", deseoso de dialogar y colaborar y que solo espera ser reconocido como un interlocutor válido.

Me parece que es en este contexto que las afirmaciones de Levinas encuentran su verdadero sentido cuando escribe: "Para nosotros el mundo de la Biblia no es un mundo de figuras sino de rostros. Están integramente alli y en relación con nosotros"14,

Cuando leo "No pensamos relaciones, somos en relación. No se trata de mediación interna sino de acción"15, recuerdo la afirmación que hago cuando se me pregunta qué implica ser judio: "Ser judio es pertenecer a un nosotros que se compromete, un nosotros que se identifica consigo mismo y se hace participe del destino histórico comín del pueblo judio, compartiendo sus valores, tradiciones y cultura, cuya base está enraizada en la Torá. Una Torat-Jayim, enseñanza de vida que hay que estudiar, cultivar y practicar"16.

Hilary Putnam, en Levinas y el judaismo ${ }^{17}$ señala dos cosas importantes acerca de nuestro autor: "que abreva de fuentes y temas judios y, paradójicamente, [...]que siendo un judio ortodoxo, universaliza el judaismo".

Y así es; él escribe: "Ser judio, es creer en la inteligencia de los fariseos y de sus maestros. Es cuestión de acceder a la fe en la Biblia a través de la inteligencia del Talmud"1.

Y tiene toda la razón, dado que el judaísmo de nuestro tiempo es de cuño farisaico, pero un farisaismo distinto al estereotipo que dan a conocer los Evangelios.

Idem, 169.

Id ibid, 169.

Tapia Adler, A. Costumbres y Tradiciones judias, Bank Leumi, Santiago de Chile, 1998, $2^{\mathrm{a}} \mathrm{ed}$.

Op. cit. 60 .

Idem, 163. 
A través de su pensamiento y su obra, Levinas permite al mundo adentrarse en el rico acervo de la sabiduría bíblica y, en especial, talmúdica, sabiduria perteneciente a un "otro", al que el mundo, durante milenios ha sindicado como tal.

\section{BIBLIOGRAFÍA}

BARYLKO, J.

El significado de la creación

Buenos Aires, Betenu, 1986.

DURANT, Will

The Story of Civilization

Ed. Simon and Schuster, N.Y., 1942.

ELLIS, M. H.

Apuntes para una teologia judia de la liberación

En: "Pasos" 1986.

LEVINAS, Emmanuel

Dificil Libertad

Buenos Aires, Calles, 2005.

La Torá con Rashi

(El Pentateuco con el comentario de Rashi)

Traducción, elucidación y comentario Aryeh Coffman. México, Editorial Jerusalem de México, $2001 / 5761$.

TAPIA ADLER, A.

Costumbres y Tradiciones Judias

$2^{\mathrm{a}}$ ed.- Santiago de Chile, Bank Leumi, 1998. 